Port Econ J (2013) 12:1-34

DOI 10.1007/s10258-013-0089-8

ORIGINAL ARTICLE

\title{
The intensive and the extensive margins: not only an international issue
}

\section{Marta Arespa}

Received: 19 September 2012 / Accepted: 4 March 2013 / Published online: 27 March 2013 (C) ISEG 2013

\begin{abstract}
Empirical evidence shows that quantity (intensive margin) and variety availability (extensive margin) have effects of different magnitude on populations' welfare. Indeed, the pattern of a market dynamics may cause changes in welfare inequality. Low income consumers benefit more from quantity than high income consumers, who are more interested in enjoying variety. These facts have been usually addressed as consequences of trade liberalization by international trade theory. However, market dynamics are also present within the borders of every country. It is important to understand what forces, unrelated with international trade, affect these dynamics. This paper explores the transmission of different real shocks into market dynamics in a new-Keynesian closed economy. Results show that the source of the shock is crucial to determine the magnitude and direction of the effects on each margin.
\end{abstract}

Keywords Extensive margin ' Innovation · Market dynamics · Endogenous entry · Real shocks

JEL Classifications E32 $\cdot$ E52

M. Arespa

Economic Theory Department, Universitat de Barcelona, Diagonal, 690 - 08034 Barcelona, Spain e-mail: marespa@gmail.com 